EPJ Web of Conferences 78, 08001 (2014)

DOI: $10.1051 /$ epjconf/20147808001

(C) Owned by the authors, published by EDP Sciences, 2014

\title{
The reactor ALLEGRO and the sustainable nuclear energy in Central Europe
}

\author{
János Gadóa \\ MTA Centre for Energy Research, Budapest, Hungary
}

\begin{abstract}
The Visegrád-4 countries (CZ, HU, PL and SK) would like to use nuclear energy on the long run. The construction of new Generation 3+ nuclear units probably belong in each country to this realm. These reactors will provide safe and cheap electric energy approximately until the end of the $21^{\text {st }}$ century. In order to use nuclear energy in the $22^{\text {nd }}$ century, sustainability of fuel supply shall be achieved by applying Generation 4 breeder reactors with fast spectrum. The corresponding research and development is organized now in the framework of the V4G4 Centre of Excellence establshed by the nuclear research institutes of the region with a strong technical support from the French CEA. The most important milestone of these efforts is the start-up of the ALLEGRO reactor that shall demonstrate the viability of the gas cooled fast reactor technology.
\end{abstract}

\section{Why G4 fast reactors?}

The nuclear reactors with thermal neutron spectrum constructed nowadays are mature: they have reached a very high safety level. Nuclear reactor fleets can satisfy the demand of secure electricity supply without carbon emission. Two problems are however undeniable:

- the uranium stocks are finite and may be exhausted within 100 years,

- the spent fuel and high level waste should be eliminated at a reasonable time scale.

Generation 4 nuclear reactors with fast neutron spectrum can solve these problems, therefore nuclear $\mathrm{R} \& \mathrm{D}$ should be concentrated on their development.

\section{Closing the fuel cycle}

Fast reactors can produce as much fissionable material (plutonium) as they consume. The closed fuel cycle makes their use sustainable.

The radiotoxicity of spent fuel and HLW can be largely reduced by using a fleet of thermal and fast reactors and a proliferation-safe advanced reprocessing.

\footnotetext{
ae-mail: janos.gado@energia.mta.hu
} 


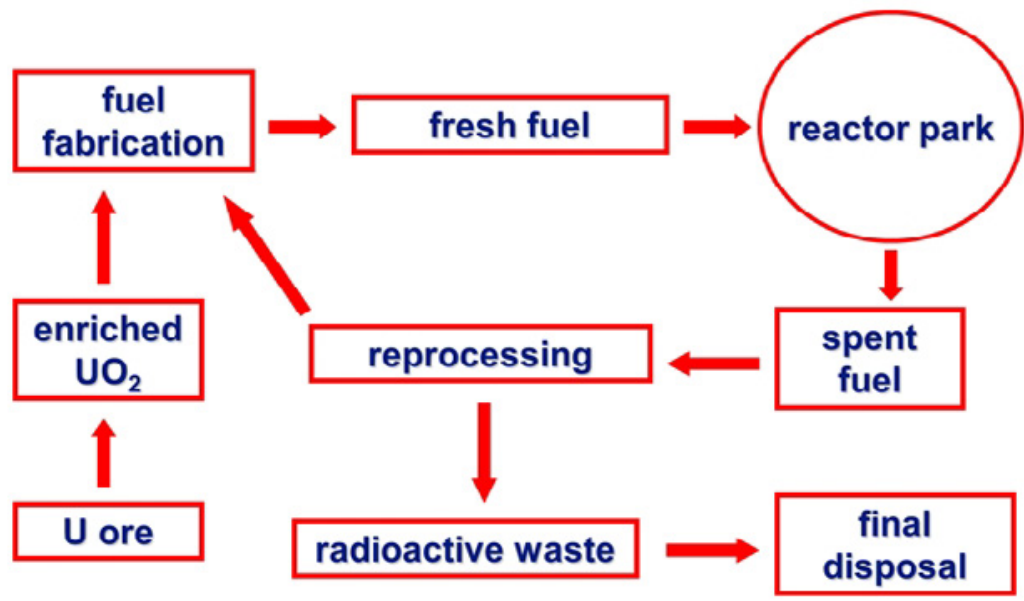

Figure 1. Scheme of the closed fuel cycle.

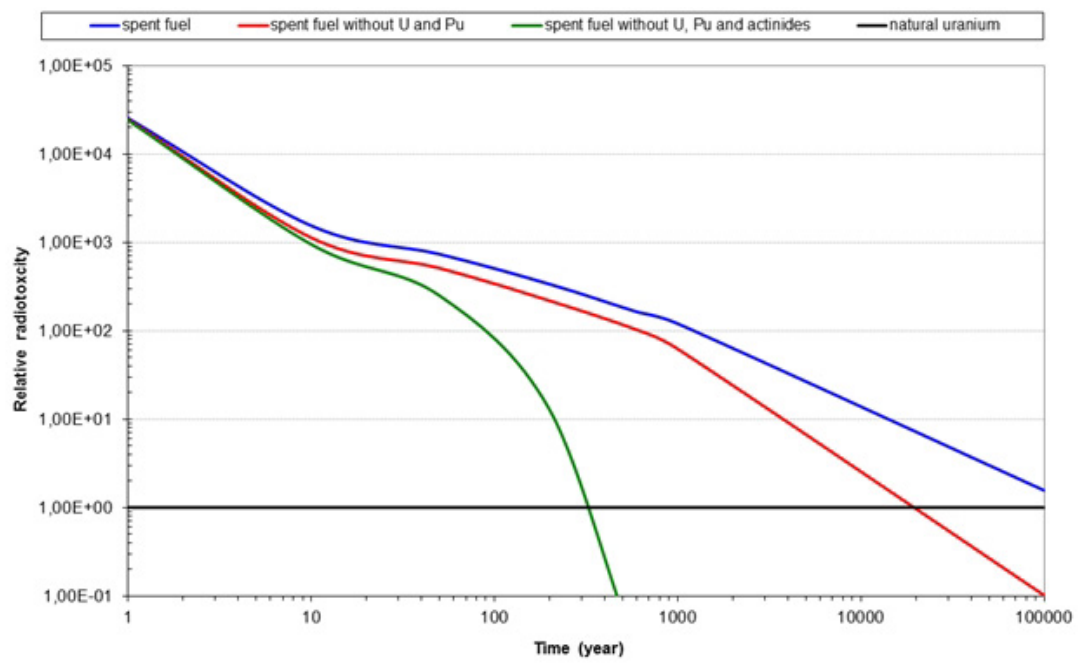

Figure 2. Radiotoxicity of spent fuel with and without reprocessing.

\section{A long term regional solution for V4}

The Visegrád-4 (V4) countries (CZ, HU, PL, SK) intend to use nuclear energy on the long run. They will construct new Generation $3+$ units in the next decades. Nuclear units with about $20 \mathrm{GW}_{\mathrm{e}}$ will be operated in G4 in the second half of the $21^{\text {st }}$ century. If the V4 countries intend to continue the use of nuclear energy in the $22^{\text {nd }}$ century, they can build up a regional solution with a joint reprocessing plant and a joint fuel fabrication plant and by combining thermal and fast reactors in the countries. In order to move into this direction the spent fuel of the Gen3+ units should be reprocessed to have the plutonium stock necessary for fuelling fast reactors in the first years of their operation. 
Wigner 111 - Colourful \& Deep Scientific Symposium

\section{Potential reactor coolant materials}

Fast neutron spectrum can be maintained by excluding light elements as coolant materials. The potential coolants are sodium, helium and lead or lead/bismuth. Each coolant has advantages and drawbacks. The most experience is collected for sodium. EU is dealing with all the three potential solutions. V4 R\&D institutes were invited by CEA (France) to take the lead in Gas Cooled Fast Reactor development. GFR can have good burning/breeding properties, moreover it can provide high temperature $\left(850^{\circ} \mathrm{C}\right)$ gas for industrial applications. GFR has to have an appropriate fuel which is still under discussion. The GFR technology and the applicability of the perspective fuel shall be demonstrated in the new reactor ALLEGRO - to be built in one of the V4 countries.

\section{ALLEGRO - the reactor}

ALLEGRO will be the demonstrator reactor of the Gas Cooled Fast Reactor (GFR). Reactor power will be $75 \mathrm{MW}_{\mathrm{th}}$, with no electricity production. The aim is to put the reactor in operation in the second part of the next decade. ALLEGRO should be as similar to the $2400 \mathrm{MW}_{\text {th }}$ GFR as possible.

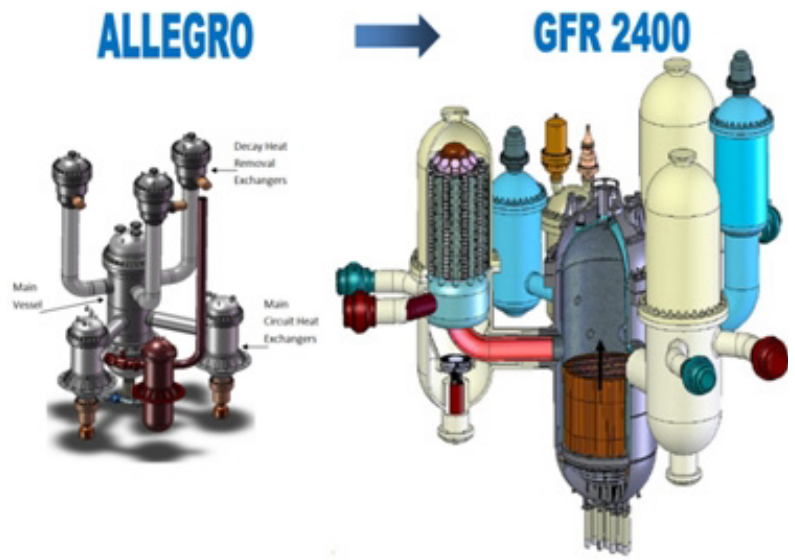

Figure 3. ALLEGRO and GFR 2400.

The existing safety concerns have to be removed on the basis of appropriate experiments and by design modifications.

\section{ALLEGRO - design}

The main safety related challenge of the current ALLEGRO design is the low thermal inertia of coolant and fuel and the high power density in the core. Therefore the basic design of CEA has been modified several times in the last years.

The technology has to be tested experimentally, partly by using problem oriented loops and other devices, partly on an electrically heated dedicated mock-up. 


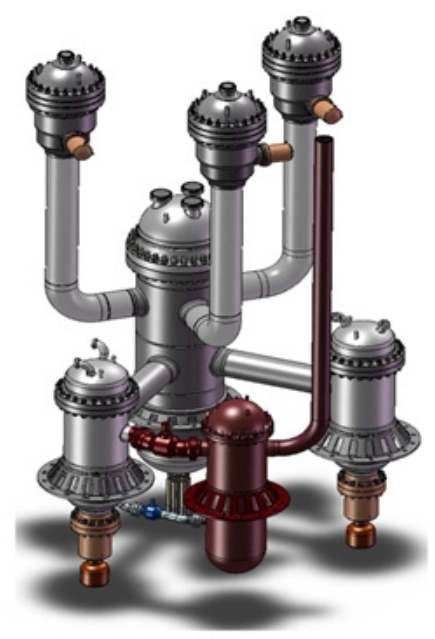

Figure 4. ALLEGRO layout.

\section{ALLEGRO - fuel}

ALLEGRO will start with MOX fuel in SS cladding, allowing for testing the innovative GFR ceramic fuel assemblies in dedicated irradiation channels of high temperature $\left(850{ }^{\circ} \mathrm{C}\right)$. Design of the first MOX fuel is under discussion since the original French design (based on Phénix fuel rods) is not practicable. The actual concept is still the use of fuel similar to ASTRID fuel (ASTRID is the sodium cooled fast reactor prototype). Applicability of this fuel in ALLEGRO conditions has to be justified by a qualification process. Low thermal inertia of the coolant is an unavoidable feature of gas cooled reactors. The gas cooled thermal reactors use graphite coated fuel making use of the advantageous thermal properties of graphite. Though graphite cannot be used for fast reactor purposes, the use of an alternative fuel instead of ASTRID-type fuel already in the first phase of ALLEGRO is under investigation.

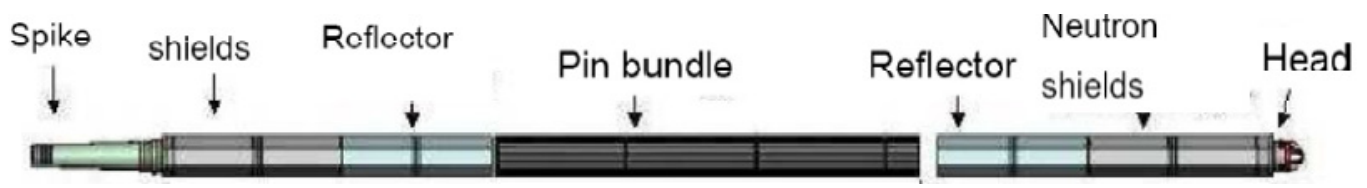

Figure 5. ALLEGRO fuel rod 
Wigner 111 - Colourful \& Deep Scientific Symposium

\section{ALLEGRO - project organization}

The Preparatory phase of the ALLEGRO project was launched by the Czech, Hungarian and Slovak nuclear R\&D organizations in 2010 with a strong participation of CEA, provider of the original design. NCBJ Poland joined in 2012.

The Preparatory phase of the ALLEGRO project aims at the preparation of documentation for decision makers deciding on ALLEGRO site and on the start of ALLEGRO licensing and construction:

- safety concept, pre-conceptual and conceptual design, safety analyses, licensing documents,

- site proposal in CZ, HU or SK for the reactor to be decided by the governments of the region.

In the next period a great attention will be paid to experimental justification of safety and fuel and system qualification. In order to organize these activities the V4G4 Centre of Excellence was established in 2013.

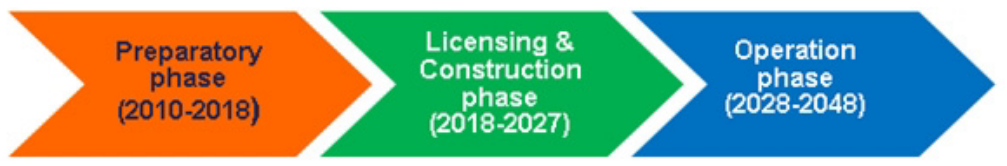

Figure 6. Timing of project phases

\section{The V4G4 Center of Excellence}

The main aim of the V4G4 Centre of Excellence is to provide the scientific basis for constructing and operating the ALLEGRO reactor. The main tool is to establish the respective research infrastructure in the co-operating V4 nuclear research institutes as follows.

- Design \& Safety Concept Research Laboratory, VUJE Trnava, SK

- GFR Technology Research Laboratory (Helium technology), ÚJV Řež, CZ

- GFR Fuel and Reprocessing Research Laboratory, MTA EK Budapest, HU

- GFR Material Research Laboratory (except fuel), NCBJ Świerk, PL.

CEA (FR) will provide scientific support to all these activities. The V4G4 Centre of Excellence will represent the ALLEGRO project in central EU organizations. 
